\title{
Risk factors for endometrial carcinoma among postmenopausal women in Sri Lanka: a case control study
}

\author{
Withanage Iresha udayangani Jayawickcrama ${ }^{1 *}$ and Chrishantha Abeysena ${ }^{2}$
}

\begin{abstract}
Background: Endometrial carcinoma burden is on the rise globally. The objective of this study was to determine the risk factors for endometrial carcinoma among postmenopausal women in Western province in Sri Lanka.

Methods: A case control study was conducted recruiting 83 incident cases of endometrial carcinoma and 332 unmatched hospital controls from all the secondary and tertiary care hospitals in the province using consecutive sampling technique. A case was defined as a postmenopausal woman who had been residing in the province for at least a period of 1 year, diagnosed to have endometrial carcinoma with histological confirmation within 3 months of the initiation of data collection of the study. Data were collected using validated interviewer administered questionnaire. Risk factor were identified through multiple logistic regression and results were expressed as adjusted odds ratios (AOR) and $95 \%$ confidence intervals (Cl).

Results: The independent risk factors of endometrial carcinoma are having family history of any type of cancer among first degree relative ( $A O R=12.6 ; 95 \%$ Cl:5.14-30.9), generalized obesity $\left(B M l \geq 25 \mathrm{~kg} / \mathrm{m}^{2}\right)(A O R=11.85 ; 95 \% \mathrm{Cl}: 5.12-27.4)$, never conceived ( $A O R=3.84 ; 95 \% \mathrm{Cl}: 1.37-10.7)$, age at menarche $\leq 11$ years ( $\mathrm{AOR}=4.07 ; 95 \% \mathrm{Cl}: 1.16-14.2)$, age $>55$ years $(A O R=4.69 ; 95 \% \mathrm{Cl}: 2.16-10.2$ ), monthly family income of $\leq 20,000$ Rupees ( $A O R=2.65 ; 95 \%$ Cl:1.31-5.39), sub-optimal consumption of deep fried food (AOR $=0.17 ; 95 \% \mathrm{Cl}: 0.06-0.46)$, and low level household activities (AOR $=2.82 ; 95 \% \mathrm{Cl}$ : 1.34-5.92).

Conclusions: There were eight independent risk factors of endometrial carcinoma specific for Sri Lankan postmenopausal women identified. Some modifiable risk factors such as generalized obesity, sub-optimal dietary practices and low level physical activities need to be addressed at primary prevention level.
\end{abstract}

Keywords: Endometrial carcinoma, Risk factors, Postmenopausal women

\section{Background}

Endometrial cancer (EC) represents the most frequent gynaecological malignancy in the developed countries, with an annual incidence of 19.5 cases per 100,000 women [1]. There were 320,000 new endometrial carcinoma cases diagnosed worldwide in 2012, accounting $4.8 \%$ of cancers among women [2]. According to the American Cancer Society [3], the probability of a woman to develop endometrial carcinoma during lifetime is 1 in 37. Population aging and rise in obesity both have joint impact on the rising incidence of endometrial carcinoma

\footnotetext{
* Correspondence: dr.iresha@yahoo.com

${ }^{1}$ Postgraduate Institute of Medicine, Colombo, Sri Lanka

Full list of author information is available at the end of the article
}

in developing countries, as evident by 2.8 times increase of age-standardized incidence rate from 3.02 cases per 100,000 women in 1991 to 11.36 cases per 100,000 women in 2010 in Taiwan [4]. When considering mortality, there were 76,000 deaths occurred due to endometrial carcinoma accounting $2.1 \%$ of cancer deaths among women, witnessing the good prognosis of the disease unless diagnosed at late stage. The five-year survival is almost $82 \%$ among the women who are diagnosed at early stages [2].

According to the latest statistics available in Sri Lanka, $4 \%$ of all reported incident cancer cases among women in 2010 were due to endometrial carcinoma. It was the eighth commonest cancer among women in Sri Lanka 
[5]. When the age group cancer distribution was compared, endometrial carcinoma was responsible for 6.4\% of all the cancers seen among women of 50-64 years, and was the fourth commonest cancer among women. Furthermore, the rising incidence of the endometrial carcinoma is evident by the increased crude incidence rate from 2.6 per 100,000 women in 2007 to 4.5 per 100,000 women in 2014, showing almost a 1.7 -fold increase [5]. As for mortality, endometrial carcinoma accounted for a crude death rate of 2.6 per 100,000 population in 2010 [5]. Increasing burden of disease morbidity worldwide, despite its low mortality in the early stage of disease still causes a huge socio-economic impact at individual, household and country level through direct and indirect costs.

Generally, the aetiology of endometrial carcinoma is multi factorial [6]. They are broadly categorized into non-modifiable and modifiable risk factor. Non-modifiable risk factors are age, race and genetic predisposition, while the modifiable life style factors are unhealthy diet and physical inactivity [7]. Further, nulliparity, obesity, diabetes, hypertension and hormone replacement therapy (HRT) are also shown as modifiable risk factors to develop endometrial carcinoma [8]. endometrial carcinoma risk is positively associated with early age at menarche, older age at menopause and use of oestrogen replacement therapy [6]. The knowledge gained by the risk factor studies conducted in Western and other Asian countries may not be directly applicable to Sri Lankan setting as the risk profile of Sri Lankan women may be different from them due to the diversity seen in social and cultural background. Hence, identifying country specific risk factors for endometrial carcinoma among Sri Lankan women would help the stake holders to plan and implement preventive programmes to reduce the magnitude of risk factors. These facts emphasize the need of identifying population-specific risk factors for endometrial carcinoma among Sri Lankan women. Therefore, the objective of this study was to determine the risk factors for endometrial carcinoma among postmenopausal women in Western province in Sri Lanka.

\section{Methods}

A hospital based unmatched case-control study was done from September 2016 to March 2017. The cases and controls were selected from the secondary and tertiary care state hospitals in the Western province where a Consultant Gynaecologist and a Consultant Pathologist were available. These hospitals were expected to represent all the patients diagnosed with endometrial carcinoma in the government sector. Western province is one of the nine provinces in Sri Lanka which includes the largest share of the population of Sri Lanka (28.7\%) [9]. It is divided into three administrative districts namely, Colombo, Gampaha and Kalutara. It consists of one
National Hospital, nine Teaching Hospitals, three District General Hospitals, four Base Hospitals, 44 Medical Officer of Health areas and many Primary Health Care Centres to provide curative, palliative and preventive health services under the state sector.

A case was defined as a postmenopausal woman who had been residing in the Western province for at least a period of 1 year, diagnosed to have endometrial carcinoma with histological confirmation within 3 months of the initiation of data collection of the study. Patients with recurrence of endometrial carcinoma, secondary endometrial carcinoma, diagnosed of any other cancer except breast cancer patients who were treated with Tamoxifen and patients who had been admitted to intensive care or high dependency unit care were excluded. The cases of endometrial carcinoma were recruited from the Oncology and Gynaecology wards and clinics. A control was defined as a postmenopausal woman who had been residing in the province for at least one-year duration prior to the commencement of the study, and confirmed as not having endometrial carcinoma by performing hysteroscopy, endometrial biopsy or curettage within 3 months of the initiation of data collection of the study. Ideally, the controls should be healthy women selected from the community where the cases belonged, since the controls should be comparable to the source population of the cases. Though, it is unethical to carry out invasive procedures to healthy women to exclude any cancer status at the time of selection. Therefore, in this study, controls were also selected from Gynaecology wards and clinics of all 14 hospitals which the cases were selected to reduce the selection bias.

The required sample size was calculated for several common risk factors of endometrial carcinoma and the largest calculated value was selected as the required sample size for the study. The values for odds ratios (OR) for different risk factors, their community prevalence were based on the available literature. The corresponding risk factor for endometrial carcinoma was obesity with an odd ratio of 2.51 and $11 \%$ of the Sri Lankan women were obese $[10,11]$. Case to control ratio was taken as 1:4. For the calculation of the sample size, power was taken as $80 \%$. The largest sample size calculated was 79 and adding $5 \%$ for non-response, the total required sample size for the cases was 83 . Therefore, the required number of controls was 332 .

An interviewer administered questionnaire was used to assess potential risk factors and it was developed based on the evidence taken through thorough literature review (Additional file 1). Quality of diet and physical activity related to cancer were assessed by validated Food Frequency Questionnaire ${ }^{12}$ (Additional file 2) and Lifetime Total Physical Activity Questionnaire [12] (Additional file 3). Further refining of the questions following the initial development of the questionnaire was 
carried out by conducting consultative meetings with the experts from the field of Community Medicine, Gynaecology and Oncology. The discussions were continued till there was consensus on the questionnaire by the group of experts. The questionnaires were pre-tested among 20 post- postmenopausal women. Face and content validity of the questionnaire was assessed. Five preintern medical officers were selected and trained as data collectors. Written consent was taken prior to the administration of the questionnaire. Steps were undertaken to minimize the disturbances to the routine work of the wards and the clinics.

Quality of diet was assessed into optimal or suboptimal consumption of energy dense food, food containing dietary fibre and anti-oxidants using validated Food Frequency Questionnaire [12]. Overconsumption of energy dense food and inadequate consumption of food containing dietary fibre and anti-oxidants were considered as sub-optimal consumption. Physical activity was defined as life time total physical activity in terms of occupational, household, sports and exercise activities and assessed by calculating the average Metabolic Equivalent of Task (MET) value for total physical activities for a week during a year by validated Life Time
Total Physical Activity Questionnaire [12]. The Metabolic Equivalent values less than 25th percentile was considered as low, more than 75th percentile was high and in between 25th to 75th percentile was taken as average physical activity in life. Exposure to electromagnetic field was defined as a distance less than $100 \mathrm{~m}$ from home to high tension wires $[13,14]$ and telecommunication towers [15]. Exposure to outdoor air pollution was defined as having the house within $100 \mathrm{~m}$ from main road or having a large industry within one $\mathrm{km}$ [16]. Long term illness was defined as diagnosis of diabetes mellitus, hypertension and hyperlipidaemia [17]. Generalized obesity was categorized based on Body Mass Index (BMI) according to the World Health Organization (WHO) definitions for adult Asians, Body Mass Index value of $25 \mathrm{~kg} / \mathrm{m}^{2}$ or more was categorized as obese. Central obese was defined as waist circumference of $80 \mathrm{~cm}$ or more based on American Diabetes Association Criteria.

Data analysis was done using the Statistical Package for the Social Sciences (SPSS)-16th version. A bivariate analysis was carried out to assess the association of each variable with the endometrial carcinoma. A multiple logistic regression was performed to identify the independent risk of each variable with endometrial carcinoma. The

Table 1 Risk of Endometrial Carcinoma associated with Socio-Demographic Factors

\begin{tabular}{|c|c|c|c|c|c|c|c|}
\hline \multirow[t]{3}{*}{ Characteristic } & \multicolumn{4}{|c|}{ Disease Status } & \multirow[t]{3}{*}{ OR } & \multirow[t]{3}{*}{$95 \% \mathrm{Cl}$} & \multirow[t]{3}{*}{$p$ value } \\
\hline & \multicolumn{2}{|c|}{ Cases $(N=83)$} & \multicolumn{2}{|c|}{ Controls $(N=332)$} & & & \\
\hline & $n$ & $\%$ & $n$ & $\%$ & & & \\
\hline \multicolumn{8}{|l|}{ Age } \\
\hline$>55$ years & 64 & 77.1 & 159 & 47.9 & 3.66 & \multirow[t]{2}{*}{$2.10-6.38$} & \multirow[t]{2}{*}{$p<0.001$} \\
\hline$\leq 55$ years & 19 & 22.9 & 173 & 52.1 & 1.0 & & \\
\hline \multicolumn{8}{|l|}{ Ethnicity } \\
\hline Sinhalese & 73 & 87.9 & 291 & 87.6 & 1.03 & \multirow[t]{2}{*}{$0.49-2.15$} & \multirow[t]{2}{*}{$p=0.94$} \\
\hline Non-Sinhalese $e^{a}$ & 10 & 12.1 & 41 & 12.4 & 1.0 & & \\
\hline \multicolumn{8}{|l|}{ Religion } \\
\hline Buddhist & 68 & 81.9 & 265 & 79.8 & 1.15 & \multirow[t]{2}{*}{$0.62-2.13$} & \multirow[t]{2}{*}{$p=0.66$} \\
\hline Non-Buddhist ${ }^{\mathrm{b}}$ & 15 & 18.1 & 67 & 20.2 & 1.0 & & \\
\hline \multicolumn{8}{|l|}{ Level of education } \\
\hline A/Level and above & 19 & 22.9 & 57 & 17.2 & 1.43 & \multirow[t]{2}{*}{$0.80-2.57$} & \multirow[t]{2}{*}{$p=0.23$} \\
\hline Below A/Level & 64 & 77.1 & 275 & 82.8 & 1.0 & & \\
\hline \multicolumn{8}{|l|}{ Employment status } \\
\hline Currently employed & 5 & 6.0 & 60 & 18.1 & 1.18 & \multirow[t]{3}{*}{$0.73-1.92$} & \multirow[t]{3}{*}{$p=0.49$} \\
\hline Previously employed ${ }^{c}$ & 40 & 48.2 & 106 & 31.9 & 1.0 & & \\
\hline Never employed & 38 & 45.8 & 166 & 50.0 & & & \\
\hline \multicolumn{8}{|c|}{ Monthly Family Income (SLR) } \\
\hline$\leq 20,000$ & 46 & 55.4 & 140 & 42.2 & 1.71 & \multirow[t]{2}{*}{$1.05-2.77$} & \multirow[t]{2}{*}{$p=0.03$} \\
\hline$>20,000$ & 37 & 44.6 & 192 & 57.8 & 1.0 & & \\
\hline
\end{tabular}

${ }^{\mathrm{a} T a m i l / M u s l i m / B u r g h e r}$ combined

${ }^{b}$ Catholic/Christian/Islam/Hindu combined

'Previously employed/currently employed combined 
variables included in the regression model were the variables that showed $p$-value of $<0.2$ in the bivariate analysis. The purposeful selection method was employed. Goodness of fit of the model was assessed by Hosmer and Lameshow test which was satisfactory $(p=0.99)$. There was no evidence of interaction and multicollinearity.

Ethical clearance to carry out the study was obtained from the Ethics Review Committee, Faculty of Medicine, University of Kelaniya, Sri Lanka.

\section{Results}

The study sample consisted of 83 patients diagnosed with endometrial carcinoma and 332 controls diagnosed with endometrial atrophy, endometrial prolapse, endometritis and atrophic vaginitis at the time of recruitment. The response rate of the cases and controls were $100 \%$.

A great majority of the cases were recruited from the hospitals located in Colombo district $(97.6 \%, n=81)$. The highest proportion of cases in the Colombo district was recruited from National Cancer Institute, Maharagama $(90.4 \% ; n=75)$. Most of the controls were also recruited from the hospitals located in Colombo district $(61.3 \% ; n=203)$, while $25.5 \%(n=85)$ from the hospitals located in Gampaha district and $13.2 \%(n=44)$ from the hospitals located in Kalutara district. The highest proportion of cases belonged to the age category of 60-69 years $(n=35 ; 42.2 \%)$ while the highest proportion of controls belonged to the age category of $50-59$ years $(n=126 ; 38.0 \%)$. The median age of cases and controls were 61.0 $(\mathrm{IQR}=56.0-67.0)$ years and $55.0(\mathrm{IQR}=50.0$ $65.0)$ years respectively.

There was a higher proportion of age $>55$ years $(p<$ 0.001 ), monthly family income of $\leq 20,000$ Sri Lanka Rupees $(p=0.03)$, unmarried $(p=0.01)$, never conceived $(p<0.001)$, nulliparity $(p<0.001)$ and menarche age $\leq$ 11 years $(p<0.001)$ in the case group as compared with those of the control group (Table 1).

There was a higher proportion of unmarried $(p=0.01)$, never conceived $(p<0.001)$, nulliparity $(p<0.001)$ and

Table 2 Risk of Endometrial Carcinoma associated with Reproductive Factors

\begin{tabular}{|c|c|c|c|c|c|c|c|}
\hline \multirow[t]{3}{*}{ Characteristic } & \multicolumn{4}{|c|}{ Disease Status } & \multirow[t]{3}{*}{ OR } & \multirow[t]{3}{*}{$95 \% \mathrm{Cl}$} & \multirow[t]{3}{*}{$p$ value } \\
\hline & \multicolumn{2}{|c|}{ Cases $(N=83)$} & \multicolumn{2}{|c|}{ Controls $(N=332)$} & & & \\
\hline & $n$ & $\%$ & $n$ & $\%$ & & & \\
\hline \multicolumn{8}{|l|}{ Marital status } \\
\hline Unmarried & 8 & 9.6 & 11 & 3.3 & 3.11 & \multirow[t]{2}{*}{$1.21-8.01$} & \multirow[t]{2}{*}{$p=0.01$} \\
\hline Ever Married & 75 & 90.4 & 321 & 96.7 & 1.0 & & \\
\hline \multicolumn{8}{|l|}{ History of conception } \\
\hline Never conceived & 17 & 20.5 & 24 & 7.2 & 3.31 & \multirow[t]{2}{*}{$1.68-6.50$} & \multirow[t]{2}{*}{$p<0.001$} \\
\hline Ever conceived & 66 & 79.5 & 308 & 92.8 & 1.0 & & \\
\hline \multicolumn{8}{|l|}{ Parity } \\
\hline Nulliparous & 19 & 22.9 & 28 & 8.4 & \multirow[t]{2}{*}{3.22} & & \\
\hline 3 or less ${ }^{a}$ & 48 & 57.8 & 245 & 73.8 & & & \\
\hline More than $3^{\mathrm{a}}$ & 16 & 19.3 & 59 & 17.8 & 1.0 & $1.69-6.12$ & $p<0.001$ \\
\hline \multicolumn{8}{|l|}{ Age at menarche } \\
\hline$\leq 11$ years & 11 & 13.3 & 10 & 3.0 & 4.92 & \multirow[t]{2}{*}{$2.01-12.02$} & \multirow[t]{2}{*}{$p<0.001$} \\
\hline$>11$ years & 72 & 86.7 & 322 & 97.0 & 1.0 & & \\
\hline \multicolumn{8}{|l|}{ Age at menopause } \\
\hline$>55$ years & 4 & 4.8 & 5 & 1.5 & 3.31 & \multirow[t]{2}{*}{$0.87-12.61$} & \multirow[t]{2}{*}{$p=0.06$} \\
\hline$\leq 55$ years & 79 & 95.2 & 327 & 98.5 & 1.0 & & \\
\hline \multicolumn{8}{|c|}{ Use of Hormone Replacement Therapy } \\
\hline \multicolumn{8}{|l|}{$(\mathrm{HRT})$} \\
\hline Ever used & 1 & 1.2 & 6 & 1.8 & 0.66 & \multirow[t]{2}{*}{$0.08-5.58$} & \multirow[t]{2}{*}{$p=0.70$} \\
\hline Never used & 82 & 98.8 & 326 & 98.2 & 1.0 & & \\
\hline \multicolumn{8}{|c|}{ Use of Hormonal contraceptives } \\
\hline Ever used & 12 & 14.5 & 58 & 17.5 & 0.80 & \multirow[t]{3}{*}{$0.40-1.56$} & \multirow[t]{2}{*}{$p=0.51$} \\
\hline Never used & 71 & 85.5 & 273 & 82.5 & 1.0 & & \\
\hline Total & 83 & 100.0 & 332 & 100.0 & & & \\
\hline
\end{tabular}

${ }^{a_{3}}$ or less $/>3$ combined 
Table 3 Risk of Endometrial Carcinoma associated with Life Style Related Factors

\begin{tabular}{|c|c|c|c|c|c|c|c|}
\hline \multirow[t]{3}{*}{ Characteristics } & \multicolumn{4}{|c|}{ Disease Status } & \multirow[t]{3}{*}{ OR } & \multirow[t]{3}{*}{$95 \% \mathrm{Cl}$} & \multirow[t]{3}{*}{$p$ value } \\
\hline & \multicolumn{2}{|c|}{ Cases $(N=83)$} & \multicolumn{2}{|c|}{ Controls $(N=332)$} & & & \\
\hline & $\mathrm{n}$ & $\%$ & $n$ & $\%$ & & & \\
\hline \multicolumn{8}{|l|}{ Dietary fibre } \\
\hline Sub-optimal ${ }^{\mathrm{a}}$ & 48 & 57.8 & 172 & 51.8 & 1.28 & \multirow[t]{2}{*}{$0.78-2.07$} & \multirow[t]{2}{*}{$p=0.32$} \\
\hline Optimal & 35 & 42.2 & 160 & 48.2 & 1.0 & & \\
\hline \multicolumn{8}{|l|}{ Anti-oxidants } \\
\hline Sub-optimal ${ }^{a}$ & 41 & 49.4 & 196 & 59.0 & 0.67 & \multirow[t]{2}{*}{$0.42-1.10$} & \multirow[t]{2}{*}{$p=0.11$} \\
\hline Optimal & 42 & 50.6 & 136 & 41.0 & 1.0 & & \\
\hline \multicolumn{8}{|l|}{ Energy dense food } \\
\hline Sub-optimal ${ }^{a}$ & 2 & 2.4 & 27 & 8.1 & 0.28 & \multirow[t]{2}{*}{$0.06-1.20$} & \multirow[t]{2}{*}{$p=0.06$} \\
\hline Optimal & 81 & 97.6 & 305 & 91.9 & 1.0 & & \\
\hline \multicolumn{8}{|c|}{ Lifetime total physical activity (MET hours per week per year) } \\
\hline Low $(<68.86)$ & 25 & 30.1 & 79 & 23.8 & 1.38 & \multirow[t]{3}{*}{$0.81-2.35$} & \multirow[t]{3}{*}{$p=0.23$} \\
\hline Average $(68.86-144.51)^{\mathrm{b}}$ & 45 & 54.2 & 163 & 49.1 & & & \\
\hline $\operatorname{High}(>144.51)^{\mathrm{b}}$ & 13 & 15.7 & 90 & 27.1 & 1.0 & & \\
\hline \multicolumn{8}{|l|}{ Occupational activities } \\
\hline Low $(<1.00)$ & 38 & 45.8 & 161 & 48.5 & 0.89 & \multirow[t]{3}{*}{$0.55-1.45$} & \multirow[t]{3}{*}{$p=0.66$} \\
\hline Average $(1.00-72.25)^{c}$ & 23 & 27.7 & 90 & 27.1 & & & \\
\hline $\operatorname{High}(>72.25)^{c}$ & 22 & 26.5 & 81 & 24.4 & 1.0 & & \\
\hline \multicolumn{8}{|l|}{ Household activities } \\
\hline Low $(<56.54)$ & 29 & 34.9 & 75 & 22.6 & 1.84 & \multirow[t]{3}{*}{$1.09-3.09$} & $p=0.02$ \\
\hline Average $(56.54-84.15)^{d}$ & 48 & 57.8 & 160 & 48.2 & & & \\
\hline $\operatorname{High}(>84.15)^{d}$ & 6 & 7.2 & 97 & 29.2 & 1.0 & & \\
\hline Sports and exercise activiti & & & & & & & \\
\hline Low $(<1.00)$ & 52 & 62.7 & 167 & 50.3 & 1.65 & $1.01-2.71$ & $p=0.04$ \\
\hline Average $(1.00-6.00)^{\mathrm{e}}$ & 15 & 18.1 & 85 & 25.6 & & & \\
\hline High $(>6.00)^{\mathrm{e}}$ & 16 & 19.3 & 80 & 24.1 & 1.0 & & \\
\hline Generalized Obesity & & & & & & & \\
\hline Obese & 71 & 85.6 & 142 & 42.8 & 7.92 & $4.14-15.1$ & $p<0.001$ \\
\hline Non-obese & 12 & 14.4 & 190 & 57.2 & & & \\
\hline Central Obesity- & & & & & & & \\
\hline Centrally obese & 73 & 88.0 & 218 & 65.7 & 3.81 & $1.89-7.67$ & $p<0.001$ \\
\hline Normal & 10 & 12.0 & 114 & 34.3 & 1.0 & & \\
\hline Exposure to passive smokir & & & & & & & \\
\hline Yes & 31 & 37.3 & 76 & 22.9 & 2.01 & $1.20-3.35$ & $p=0.01$ \\
\hline No & 52 & 62.7 & 256 & 77.1 & 1.0 & & \\
\hline Hair Dye & & & & & & & \\
\hline Ever used & 29 & 34.9 & 145 & 43.7 & 0.69 & $0.42-1.14$ & $p=0.15$ \\
\hline Never used & 54 & 65.1 & 187 & 56.3 & 1.0 & & \\
\hline Exposure to Electromagnet & & & & & & & \\
\hline Yes & 16 & 19.3 & 73 & 22.0 & 0.85 & $0.46-1.55$ & $p=0.59$ \\
\hline No & 67 & 80.7 & 259 & 78.0 & 1.0 & & \\
\hline
\end{tabular}


Table 3 Risk of Endometrial Carcinoma associated with Life Style Related Factors (Continued)

\begin{tabular}{|c|c|c|c|c|c|c|c|}
\hline \multirow[t]{3}{*}{ Characteristics } & \multicolumn{4}{|c|}{ Disease Status } & \multirow[t]{3}{*}{ OR } & \multirow[t]{3}{*}{$95 \% \mathrm{Cl}$} & \multirow[t]{3}{*}{$p$ value } \\
\hline & \multicolumn{2}{|c|}{ Cases $(N=83)$} & \multicolumn{2}{|c|}{ Controls $(N=332)$} & & & \\
\hline & $\mathrm{n}$ & $\%$ & $\mathrm{n}$ & $\%$ & & & \\
\hline \multicolumn{8}{|c|}{ Exposure to Pesticide/weedicide } \\
\hline Direct exposure & 12 & 14.5 & 15 & 4.5 & 2.50 & $1.17-5.32$ & $p=0.28$ \\
\hline Indirect exposure & 0 & 0.0 & 6 & 1.8 & & & \\
\hline No exposure & 71 & 85.5 & 311 & 93.7 & 1.0 & & \\
\hline \multicolumn{8}{|c|}{ Exposure to air pollution } \\
\hline Yes & 46 & 55.4 & 167 & 50.3 & 1.23 & $0.76-1.99$ & $P=0.40$ \\
\hline No & 37 & 44.6 & 165 & 49.7 & 1.0 & & \\
\hline Total & 83 & 100.0 & 332 & 100.0 & & & \\
\hline
\end{tabular}

a Sub-optimal: Inadequate consumption of dietary fibre, inadequate consumption of anti-oxidants and over consumption of energy dense food

$b, c, d, e$ Average and high levels of physical activity categories amalgamated for bivariate analysis

menarche age $\leq 11$ years $(p<0.001)$ in the case group as compared with those of the control group (Table 2).

There was a higher proportion of women with generalized obesity and central obesity $(p<0.001)$, and exposure to passive smoking $(p=0.01)$ in the case group as compared with those of the control group (Table 3 ).

There was a higher proportion of hypertension $(p=0.02)$ and use of Losartan for $\geq 5$ years $(p=0.03)$, use of Tamoxifen $(p<0.001)$, ever exposure of $x$-ray radiation $(p<0.001)$, past history of adenomyosis $(p=0.01)$ and family history of any type of cancer $(p<0.001)$ in the case group as compared with those of the control group (Table 4).

There were 10 variables retained in the final regression model of the 32 variables that were included. The sample size for the final regression model included 415 postmenopausal women with 83 cases and 415 controls. After adjusting the variables, having family history of any type of cancer (OR $=12.61,95 \%$ CI:5.14-30.94), generalized obesity $(\mathrm{OR}=11.85,95 \%$ CI:5.12-27.43), never conceived $(\mathrm{OR}=3.84,95 \% \mathrm{CI}: 1.37-10.71)$, age more than 55 years $(\mathrm{OR}=4.69,95 \% \mathrm{CI}: 2.16-10.21)$, monthly family income $\leq 20,000$ Sri Lankan Rupees $(\mathrm{OR}=2.65,95 \% \mathrm{CI}: 1.31-5.39)$, age at menarche $\leq 11$ years $(\mathrm{OR}=4.07,95 \% \mathrm{CI}: 1.16-14.21)$, and low level household activities ( $\mathrm{OR}=2.82$, 95\% CI:1.34-5.92) were found to be associated with an increased risk of endometrial carcinoma (Table 5).

\section{Discussion}

The independent risk factors of endometrial carcinoma among postmenopausal women were having family history of any type of cancer, generalized obesity, never conceived, sub-optimal consumption of deep fried food, low level household activities, age more than 55 years, monthly family income $\leq$ Sri Lankan Rupees 20,000 and age at menarche $\leq 11$ years.

In the present study, family history of cancer among first degree relative had shown a strong association with endometrial carcinoma. Several studies had also assessed the association of family history of cancer among first degree relative with endometrial carcinoma and the results showed consistencies $[18,19]$ as well as inconsistencies [20] with the findings of the present study.

Another important finding of the present study was being generally obese increased the risk of developing endometrial carcinoma. This result is in line with the findings of two other studies [21,22]. All these evidence in line with the present study reiterate the importance of maintaining BMI within the normal range recommended for women in preventing endometrial carcinoma and to be emphasized in health promotion programme for women in Sri Lanka.

The present study identified having history of never conception as an independent risk factor for endometrial carcinoma. This finding was in line with another study [23].

In the present study, sub-optimal consumption of deep fried food was an independent association with endometrial carcinoma. Contrary to the common belief 'frequent consumption of deep fried food could cause cancer', present study identified sub optimal consumption of deep fried food with a protective effect in developing endometrial carcinoma. The lifestyle changes among the cases due to the diagnosis of the disease would have influenced the validity of data. Several studies found that there was no significant association of dietary practices and developing endometrial carcinoma [24-26] while one study [27] showed a significant association with endometrial carcinoma with a protective effect in consumption of butter and coffee. Due to the differences of the tools and the methodologies used to assess the dietary practices in the above studies, meaningful comparison cannot be done.

Another independent risk factor for endometrial carcinoma was low level lifetime household activities. A study [28] revealed a reduced risk of endometrial carcinoma among women who spent $90 \mathrm{~min}$ or more of nonoccupational physical activities compared to women who 
Table 4 Risk of Endometrial Carcinoma associated with Medical Conditions

\begin{tabular}{|c|c|c|c|c|c|c|c|}
\hline \multirow[t]{3}{*}{ Characteristics } & \multicolumn{4}{|l|}{ Disease Status } & \multirow[t]{3}{*}{ OR } & \multirow[t]{3}{*}{$95 \% \mathrm{Cl}$} & \multirow[t]{3}{*}{$p$ value } \\
\hline & \multicolumn{2}{|l|}{ Cases $(N=83)$} & \multicolumn{2}{|l|}{ Controls $(N=332)$} & & & \\
\hline & $n$ & $\%$ & $n$ & $\%$ & & & \\
\hline \multicolumn{8}{|c|}{ Duration of Diabetes Mellitus } \\
\hline$\geq 5$ years & 18 & 21.7 & 59 & 17.8 & 1.28 & $0.71-2.32$ & $p=0.41$ \\
\hline$<5$ years & 65 & 78.3 & 273 & 82.2 & 1.0 & & \\
\hline \multicolumn{8}{|c|}{ Duration of Hypertension } \\
\hline$\geq 5$ years & 25 & 30.1 & 62 & 18.7 & 1.88 & $1.10-3.23$ & $p=0.02$ \\
\hline$<5$ years & 58 & 69.9 & 270 & 81.3 & 1.0 & & \\
\hline \multicolumn{8}{|c|}{ Duration of Hyperlipidemia } \\
\hline$\geq 5$ years & 10 & 12.0 & 34 & 10.2 & 1.20 & $0.57-2.54$ & $p=0.63$ \\
\hline$<5$ years & 73 & 88.0 & 298 & 89.8 & 1.0 & & \\
\hline \multicolumn{8}{|c|}{ On long term medication } \\
\hline$\geq 5$ years & 34 & 41.0 & 102 & 30.7 & 1.56 & $0.95-2.56$ & $p=0.07$ \\
\hline$<5$ years & 49 & 59.0 & 230 & 69.3 & 1.0 & & \\
\hline \multicolumn{8}{|l|}{ Tamoxifen } \\
\hline Yes & 4 & 4.8 & 0 & 0.3 & 5.20 & $4.27-6.34$ & $p<0.001$ \\
\hline No & 79 & 95.2 & 332 & 99.7 & 1.0 & & \\
\hline \multicolumn{8}{|c|}{ Exposure to any $x$-ray } \\
\hline Ever exposed & 63 & 75.9 & 185 & 55.7 & 2.50 & $1.45-4.33$ & $p<0.001$ \\
\hline Never exposed & 20 & 24.1 & 147 & 44.3 & 1.0 & & \\
\hline \multicolumn{8}{|l|}{ Fibroid } \\
\hline Yes & 12 & 14.5 & 80 & 24.1 & 0.53 & $0.27-1.03$ & $p=0.06$ \\
\hline No & 71 & 85.5 & 252 & 75.9 & 1.0 & & \\
\hline \multicolumn{8}{|l|}{ Endometriosis } \\
\hline Yes & 20 & 24.1 & 72 & 21.7 & 1.15 & $0.65-2.02$ & $p=0.63$ \\
\hline No & 63 & 75.9 & 260 & 78.3 & 1.0 & & \\
\hline \multicolumn{8}{|l|}{ Adenomyosis } \\
\hline Yes & 8 & 9.6 & 74 & 22.3 & 0.37 & $0.17-0.81$ & $p=0.01$ \\
\hline No & 75 & 90.4 & 258 & 77.7 & 1.0 & & \\
\hline \multicolumn{8}{|l|}{$\mathrm{PID}^{1}$} \\
\hline Yes & 4 & 4.8 & 14 & 4.2 & 1.15 & $0.37-3.59$ & $p=0.81$ \\
\hline No & 79 & 95.2 & 318 & 95.8 & 1.0 & & \\
\hline \multicolumn{8}{|l|}{ Vaginal Infection } \\
\hline Yes & 9 & 10.8 & 36 & 10.5 & 1.03 & $0.47-2.24$ & $p=0.93$ \\
\hline No & 74 & 89.2 & 296 & 89.5 & 1.0 & & \\
\hline \multicolumn{8}{|l|}{ History of PCOD ${ }^{2}$} \\
\hline Yes & 8 & 9.6 & 17 & 5.1 & 1.98 & $0.82-4.75$ & $p=0.12$ \\
\hline No & 75 & 90.4 & 315 & 94.9 & 1.0 & & \\
\hline \multicolumn{8}{|c|}{ Family history of any type of cancer } \\
\hline Yes & 31 & 37.3 & 19 & 5.7 & 9.82 & $5.17-$ & $p<0.001$ \\
\hline No & 52 & 62.7 & 313 & 94.3 & 1.0 & 18.66 & \\
\hline Total & 83 & 100.0 & 332 & 100.0 & & & \\
\hline
\end{tabular}


Table 5 Adjusted Odds Ratios for Independent risk factors of Endometrial Carcinoma

\begin{tabular}{|c|c|c|c|c|c|c|}
\hline \multirow[t]{2}{*}{ Independent risk factors } & \multirow[t]{2}{*}{$\beta$} & \multirow{2}{*}{$\begin{array}{l}\text { SE } \\
(\beta)\end{array}$} & \multirow[t]{2}{*}{$\mathrm{AOR}^{\mathrm{a}}$} & \multicolumn{2}{|c|}{$95 \% \mathrm{Cl}$ for $\mathrm{AOR}^{\mathrm{a}}$} & \multirow[t]{2}{*}{$p$ value } \\
\hline & & & & Lower & Upper & \\
\hline Having family history of any type of cancer & 2.53 & 0.46 & 12.61 & 5.14 & 30.94 & $p<0.001$ \\
\hline $\begin{array}{l}\text { Generalized obesity } \\
\mathrm{BMI} \geq 25 \mathrm{Kgm}^{-2}\end{array}$ & 2.47 & 0.43 & 11.85 & 5.12 & 27.43 & $p<0.001$ \\
\hline Never conceived & 1.34 & 0.52 & 3.84 & 1.37 & 10.71 & $p=0.01$ \\
\hline Age more than 55 years & 1.55 & 0.39 & 4.69 & 2.16 & 10.21 & $p<0.001$ \\
\hline Monthly family Income $\leq$ Rs.20,000 & 0.97 & 0.36 & 2.65 & 1.31 & 5.39 & $p=0.007$ \\
\hline Age at menarche $\leq 11$ years & 1.40 & 0.64 & 4.07 & 1.16 & 14.21 & $p=0.03$ \\
\hline Sub-optimal consumption of deep fried food & -1.74 & 0.49 & 0.17 & 0.06 & 0.46 & $p<0.001$ \\
\hline Low level household activities & 1.03 & 0.38 & 2.82 & 1.34 & 5.92 & $p=0.006$ \\
\hline Central obesity $>80 \mathrm{~cm}$ & 0.79 & 0.45 & 2.21 & 0.92 & 5.31 & $p=0.07$ \\
\hline Ever exposed to X-ray & 0.61 & 0.38 & 1.85 & 0.88 & 3.87 & $p=0.10$ \\
\hline Constant & -6.20 & 0.80 & .002 & & & $p<0.001$ \\
\hline
\end{tabular}

${ }^{\mathrm{a} A O R}$ Adjusted Odds Ratio

spent less than 30 min per day. Another study [29] also revealed a decreased risk of endometrial carcinoma associated with leisure time activities.

In the present study, age 55 years or more found to be a significant risk factor for endometrial carcinoma. The risk of developing endometrial carcinoma increases with age [30]. Though, age being a non-modifiable factor, this finding indicates that preventive interventions for endometrial carcinoma should be targeted at young women to prevent the development of the disease at the later ages in life.

Further, present study found that monthly family income of Sri Lankan Rupees 20,000 or less was an independent association with endometrial carcinoma. This could be due to various unhealthy practices related to low family income such as unhealthy dietary practices, and poor care seeking behaviour [31].

The present study identified menarcheal age of 11 years or less as an independent risk factor for endometrial carcinoma. The findings are consistent with the finding of another study [32].

Several studies reported that history of diabetes mellitus and hypertension are associated with increased risk of endometrial carcinoma [33-36]. In the current study, diabetes mellitus didn't show any significant association though hypertension increased the risk of endometrial carcinoma in the bivariate analysis. This contradictory results could be explained in part by the method of assessment of the two conditions.

Generalizability of the results was ensured by selecting a representative sample of cases and controls from all government hospitals in the Western province with facilities to diagnose and treat the endometrial carcinoma patients.

A major limitation in case control study design is selection bias. Ideally, the controls should be selected from the community where the cases belonged, since the controls should be comparable to the source population of the cases. Though, it is unethical to carry out invasive procedures to healthy women to exclude any cancer status at the time of selection. For assessing the association of family history of any type of cancer and endometrial carcinoma, the patients diagnosed with EC with or suspected lynch syndrome should be excluded, as endometrial carcinoma - lynch syndrome relationship dilutes the effect of family history on endometrial carcinoma. In the present study, the influence of hereditary component in endometrial carcinoma was not assessed due to limited resource and time in the local setup. This was another limitation of the study. Selection of several common risk factors of endometrial carcinoma to calculate the sample size would result in lack of statistical power for other important risk factors with marginal effect size leading to wide confidence intervals due to the limited sample size. This is considered as a limitation of the study.

\section{Conclusions}

Of the potential risk factors, age more than 55 years, monthly family income of Sri Lankan Rupees 20,000 or less, history of never conception, early menarche, having family history of any type of cancer, generalized obesity, sub-optimal consumption of deep fried food and low level household activities were the independent risk factors of endometrial carcinoma specific for Sri Lankan postmenopausal women. The importance of inculcating healthy dietary and physical activity practices since the childhood need to be advocated and addressed through public awareness programmes. Community level educational programmes on planning healthy meals at home should be organized to uplift the knowledge of women who are usually responsible in deciding main meal at home. 


\section{Supplementary information}

Supplementary information accompanies this paper at https://doi.org/10. 1186/s12889-019-7757-2.

Additional file 1. Interviewer Administered Questionnaire for assessing Risk Factors for Endometrial Carcinoma.

Additional file 2. Food Frequency Questionnaire.

Additional file 3. Life Time Total Physical Activity Questionnaire.

\section{Abbreviations}

AOR: Adjusted Odds Ratios; BMI: Body Mass Index; Cl: confidence intervals; EC: Endometrial cancer; HRT: Hormone Replacement Therapy;

IQR: Interquartile Range; MET: Metabolic Equivalent of Task; OR: Odds Ratio; SPSS: Statistical Package for the Social Sciences; WHO: World Health Organization

\section{Acknowledgements}

The authors wish to thank the health administrators of the districts where the study was conducted, administrators and the clinicians of the health institutions, study participants and data collectors.

\section{Authors' contributions}

WIUJ was involved in the conceptualization of the research, literature search, data extraction, data analysis and drafting of the initial manuscript. CA was involved in conceptualization of the research, literature search, data analysis and editing the manuscript. All authors read the final manuscript.

\section{Funding}

This study was funded by Second Health Sector Development Project (SHSDP) of Ministry of Health, Nutrition and Indigenous Medicine, under the grant number SHSDP/RG/2017/25. The funding body played no role in study design, data collection and analysis, decision to publish, or preparation of the manuscript.

\section{Availability of data and materials}

The datasets used and/or analysed during the current study are available from the corresponding author on reasonable request.

\section{Ethics approval and consent to participate}

Ethical clearance to carry out the study was obtained from the Ethics Review Committee, Faculty of Medicine, University of Kelaniya, Sri Lanka.

\section{Consent for publication}

Not applicable.

\section{Competing interests}

The authors declare that they have no competing interests.

\section{Author details}

${ }^{1}$ Postgraduate Institute of Medicine, Colombo, Sri Lanka. ${ }^{2}$ Department of Public Health, Faculty of Medicine, University of Kelaniya, Ragama, Sri Lanka.

Received: 13 June 2019 Accepted: 7 October 2019

Published online: 28 October 2019

\section{References}

1. Bohiltea R, Furtunescu F, Dosius M, Cîrstoiu M, Radoi V Baros A, Bohîltea LC. Evaluation of endometrial cancer epidemiology in Romania. J Med Life. 2015;8(2):218-25.

2. Ferlay J, Soerjomataram I, Dikshit R, Eser S, Mathers C, Rebel M, Bray F. Cancer incidence and mortality worldwide: sources, methods and major patterns in GLOBOCAN 2012. Int J Cancer. 2015;136(5):359-86. https://doi. org/10.1002/ijc.29210 PMID:25220842

3. American Cancer Society. Cancer Facts \& Figures 2012 [internet]. Atlanta: American Cancer Society; 2015. Available from https://www.cancer.org/ research/cancer-facts-statistics/all-cancer-facts-figures/cancer-facts-figures-2 012.html

4. Lai JC, Weng C, Huang S, Huang N, Chou Y, Wang C, Wang K. Incidence and lifetime risk of uterine corpus cancer in Taiwanese women from 1991 to 2010. Taiwan J Obstet Gynecol. 2017;56(1):68-72. https://doi.org/10.1016/ j.tjog.2015.09.010.

5. National Cancer Control Programme. Cancer incidence data 2010. Sri Lanka: National Cancer Control Programme; 2016. Available from http://nccp. health.gov.IK/images/PDF_PUBLICATIONS/Cancer_Incidence_Data_2010.pdf

6. Parslov M, Lidegaard O, Klintorp S, Pedersen B, Jønsson L, Eriksen PS, Ottesen B. Risk factors among young women with endometrial cancer: a Danish case-control study. Am J Obstet Gynecol. 2000;182(1):23-9.

7. Bittoni MA, Fisher JL, Fowler JM, Maxwell GL, Paskett ED. Assessment of the effects of severe obesity and lifestyle risk factors on stage of endometrial cancer. Cancer Epidemiol Biomark Prev. 2013;22(1):76-81. https://doi.org/10. 1158/1055-9965.EPI-12-0843.

8. Inoue M, Okayama A, Fujith M, Enomata T, Tanizawa O, Ueshima H. A case control study on risk factors for uterine cancer in Japan. Jpn J Cancer Res. 1994:85(4):346-50.

9. Census and Statistics. Population Survey Report. Sri Lanka: Department of Census and Statistics; 2012. Available from http://www.statistics.gov.lk/ PopHouSat/CPH2011/Pages/Activities/Reports/FinalReport/FinalReportE.pdf

10. Bjørge T, Engeland A, Tretli S, Weiderpass E. Body size in relation to cance of the uterine corpus in 1 million Norwegian women. Int J Cancer. 2006; 120:378-83. https://doi.org/10.1002/ijc.22260.

11. Katulanda P, Jayawardena MAR, Sheriff MHR, Constantine GR, Matthews DR. Prevalence of overweight and obesity in Sri Lankan adults. Obes Rev. 2010; 11(11):751-6. https://doi.org/10.1111/j.1467-789X.2010.00746.x

12. Kumari PBVR. Risk factors and risk assessment of breast cancer among women in the district of Colombo. Colombo: Post Graduate Institute of Medicine, University of Colombo; 2013.

13. Kroll M, Swanson J, Vincent TJ, Draper GJ. Childhood cancer and magnetic fields from high-voltage power lines in England and Wales: a case-control study. Br J Cancer. 2010;103(7):1122-7. https://doi.org/10.1038/sj.bjc.6605795.

14. Savitz DA, Philips A, Carroll MO, Henshaw D. Adult cancers near highvoltage power lines. J Epidemol. 2013;24(5):782-3. https://doi.org/10.1097/ EDE.0b013e31829f3cb3.

15. Chakraborty C. Determination of safe distance limit from Cellular Base station radiation exposure using SAR analysis. Int J Comput Appl. 2013;55: $18-22$.

16. Mahalingaiah S, Hart JE, Laden F, Terry KL, Boynton-Jarrett R, Aschengrau A, Missmer SA. Adult air pollution exposure and risk of uterine leiomyoma in the nurses' health study II. Epidemiology. 2014;25(5):682-8. https://doi.org/ 10.1097/EDE.0000000000000126.

17. Rosato V, Zucchetto A, Bosetti C, Maso LD, Montella M, Pelucchi C, Vecchia CL. Metabolic syndrome and endometrial cancer risk. Ann Oncol. 2011:22: 884-9. https://doi.org/10.1093/annonc/mdq464

18. Obermair A, Youlden DR, Young JP, Lindor NM, Baron JA, Newcomb P, Jenkins MA. Risk of endometrial cancer for women diagnosed with HNPCCrelated colorectal carcinoma. Int J Cancer. 2010;127(11):2678-84. https://doi. org/10.1002/ijc.25501.

19. Cook LS, Nelson HE, Stidley CA, Dong Y, Round PJ, Amankwah EK, Friedenreich CM. Endometrial cancer and a family history of cancer. Gynecol Oncol. 2013;130(2):334-9. https://doi.org/10.1016/j.ygyno.2013.04.053.

20. Olson JE, Sellers TA, Anderson KE, Folsom AR. Does a family history of cancer increase the risk for postmenopausal endometrial carcinoma. J Cancer. 1999;85(11):2444-9 Available from http://www.ncbi.nlm.nih.gov/ pubmed/10357416.

21. Xu WH, Xiang YB, Zheng W, Zhang X, Ruan ZX, Cheng JR, Shu XO. Weight history and risk of endometrial cancer among Chinese women. Int Epidemiol. 2006;35(1):159-66. https://doi.org/10.1093/ije/dyi223.

22. Gao Y, Dai $X$, Chen L, Lee AC, Tong M, Wise M, Chen Q. Body mass index is positively associated with endometrial cancer in Chinese women, especially prior to menopause. J Cancer. 2016;7(9):1169-73. https://doi.org/10.7150/jca.15037.

23. Xu WH, Xiang YB, Ruan ZX, Zheng W, Cheng JR, Dai Q, Shu XO. (2004). Menstrual and reproductive factors and endometrial cancer risk: results from a population-based case-control study in urban Shanghai. Int J Cancer. 2004:108(4):613-9. https://doi.org/10.1002/ijc.11598.

24. Salazar-Martinez E, Lazcano-Ponce E, Sanchez-Zamorano LM, Gonzalez Lira G. Escudero-DE los Rios P. Hernandez-Avila M. dietary factors and endometrial cancer risk. Results of a case-control study in Mexico. Int J Gynecol Cancer. 2005;15(5):938-45. https://doi.org/10.1111/j.1525-1438. 2005.00253

25. Cui X, Rosner B, Willett WC, Hankinson SE. Dietary fat, fibre, and carbohydrate intake in relation to risk of endometrial cancer. Cancer 
Epidemiol Biomark Prev. 2011;1089:978. https://doi.org/10.1158/1055-9965 EPI-10-1089.

26. Canchola AJ, Lace JV, Bernstein L, Horn-Ross PL. Dietary patterns and endometrial cancer risk in the California teachers study cohort. Cancer Causes Control. 2015;26(4):627-34. https://doi.org/10.1007/s10552-015-0552-1.

27. Merritt M, Tzoulaki I, Tworoger SS, De Vivo I, Hankinson SE, Fernandes J,

Dahm CC. Investigation of dietary factors and endometrial cancer risk using a nutrient-wide association study approach in the EPIC and Nurses' health study (NHS) and NHSII. Cancer Epidemiol Biomark Prev. 2015;24(2):466-71. https://doi.org/10.1158/1055-9965.EPI-14-0970.

28. Schouten L, Goldbohm RA, Van Den Brandt PA. Anthropometry, physical activity, and endometrial cancer risk: results from the Netherlands cohort study. J Natl Cancer Inst. 2004;96(21):1635-8.

29. Friedenreich CM, Cook LS, Magliocco AM, Duggan MA, Courneya KS. Casecontrol study of lifetime total physical activity and endometrial cancer risk Cancer Causes Control. 2010;21(7):1105-16. https://doi.org/10.1007/s10552010-9538-1.

30. Creasman WT. Endometrial cancer: incidence, prognostic factors, diagnosis, and treatment. Semin Oncol. 1997;24:1-140.

31. Heidary F, Rahimi A, Gharebaghi R. Poverty as a risk factor in human cancers. Iran J Public Health. 2013;42(3):341-3.

32. Karageorgi S, Hankinson SE, Kraft P, De Vivo I. Reproductive factors and postmenopausal hormone use in relation to endometrial cancer risk in the Nurses' health study cohort 1976-2004. Int J Cancer. 2010;126(1):208-16. https://doi.org/10.1002/ijc.24672.

33. Terry P, Baron JA, Weiderpass E, Yuen J, Lichtenstein P, Nyren O. Lifestyle and endometrial cancer risk: a cohort study from the Swedish twin registry. Int J Cancer. 1999;82:38-42.

34. Friberg E, Mantzoros CS, Wolk A. Diabetes and risk of endometrial cancer: a population-based prospective cohort study. Cancer Epidemiol Biomark Prev. 2007;16(2):276-80. https://doi.org/10.1158/1055-9965.EPI-06-0751.

35. Friberg E, Orsini N, Mantzoros CS, Wolk A. Diabetes mellitus and risk of endometrial cancer: a meta-analysis. Diabetologia. 2007;50(7):1365-74. https://doi.org/10.1007/s00125-007-0681-5.

36. American Cancer Society. Cancer Facts \& Figures 2015. Atlanta: American Cancer Society; 2015. Available from https://www.cancer.org/content/dam/ cancer-org/research/cancer-facts-and-statistics/annual-cancer-facts-andfigures/2015/cancer-facts-and-figures-2015.pdf

\section{Publisher's Note}

Springer Nature remains neutral with regard to jurisdictional claims in published maps and institutional affiliations.

Ready to submit your research? Choose BMC and benefit from:

- fast, convenient online submission

- thorough peer review by experienced researchers in your field

- rapid publication on acceptance

- support for research data, including large and complex data types

- gold Open Access which fosters wider collaboration and increased citations

- maximum visibility for your research: over $100 \mathrm{M}$ website views per year

At BMC, research is always in progress.

Learn more biomedcentral.com/submissions 